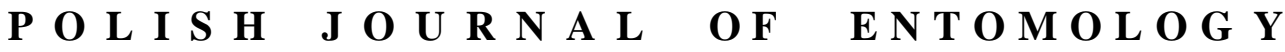

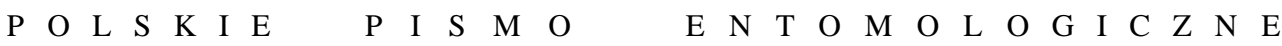

VOL. 85: 311-323

Lublin

30 September 2016

DOI: $10.1515 /$ pjen-2016-0017

\section{Seasonal occurrence of the Mediterranean fruit fly, Ceratitis capitata (WiEdEMANN, 1824) (Diptera: Tephritidae) in southern Syria}

\author{
MOHAMMED MANSOUR ${ }^{*}$, FATER MOHAMAD \\ Energy Commission of Syria, P. O. Box 6091, Damascus, Syria
}

\begin{abstract}
Population fluctuations of the Mediterranean fruit fly (medfly), Ceratitis capitata, were investigated between 1999 and 2001 at several locations representing fruit production areas in the southern part of Syria (Damascus Ghota, Zabadani, Sargaiah, Rankus, Orneh and Ain Al-Arab). Medfly adults were monitored weekly all year around using Jackson traps baited with trimedlure dispensers. Larvae were also sampled in Damascus Ghota by collecting fruits from ripe or ripening fruit trees and recording the number of larvae emerged from these fruits. In addition, suspected overwintering refuges were sampled at weekly intervals during the three coldest months of the year (December - February) and the number of collected larvae was recorded. The results of trap catches and fruit sampling studies showed a similar pattern of occurrence of medfly populations in the study areas, particularly in Damascus Ghota, during the three years of the study. In Damascus Ghota, flies were caught continuously from early June to late December with some variability between years. Two distinct periods of high fly activity were observed: the first one occurred in August and the second in November with a much higher amplitude. In general, seasonal fluctuations in the pattern of occurrence were influenced by differences in temperature and abundance of preferred host fruits. Traps on fig Ficus carica and oriental persimmon Diospyros kaki trees caught the highest numbers of flies, and fruits collected from these trees showed the highest level of infestation, reaching $100 \%$ for fig fruit late in the season. Sampling fruits (in Damascus Ghota) from trees during the three coldest months of the year showed that a small population of medfly larvae was able to survive winter conditions in prickly pear Opuntia vulgaris fruit left on the trees. In the other areas of the study (Zabadani, Sargaiah, Rankus, Orneh and Ain Al-Arab), only a few flies were caught.
\end{abstract}

KEY WORDS: Insecta, Ceratitis capitata, seasonal occurrence, Syria.

\footnotetext{
* Corresponding author: ascientific@aec.org.sy
} 


\section{INTRODUCTION}

The Mediterranean fruit fly, or medfly, Ceratitis capitata (WIEDEmann, 1824) (Diptera: Tephritidae), is one of the most destructive insect pests of fruit trees in the world (LIQUIDO et al. 1991, SZYNISZEWSKA and TATEM 2014). Worldwide, the larvae of this fly attack more than 200 wild or cultivated hosts (KARPATI 1983, LIQUIDO et al. 1991). Although indigenous to tropical Africa (KouRTI et al. 1992), the larvae of this species have developed a remarkable ability to survive the low winter temperatures of temperate regions within certain types of host fruits (PAPADOPOULOS et al. 1996). Consequently, it has become established not only in other tropical areas but also in several temperate regions on five continents (LIQUIDO et al. 1991), including the Mediterranean region (FIMIANI 1989). In addition, the medfly is a quarantine pest in many parts of the world (EPPO 2009, IAEA 2013) and, consequently, trade barriers are imposed against agricultural products from infested countries.

In the Mediterranean basin, where the medfly was first discovered and derived its common name, this species takes a heavy toll of fruit production (FIMIANI 1989, KARPATI 1983). In this region, many studies have been conducted on the population dynamics of this pest, a few of them from the eastern part of the Mediterranean (GRUNBERG 1938, RIVNAY 1951, ISRAELY et al. 1997, MUSTAFA and ABDEL-JABBAR 1996, AHMAD et al. 2001).

Although the medfly has been present in the eastern Mediterranean region since the $19^{\text {th }}$ century (FIMIANI 1989), it was not officially reported from Syria until 1954 (TALHOUK 1954). The favourable temperatures throughout most of the year and the large number of fruit tree varieties in which the larvae of this fly can develop enabled this species to colonize most habitats in the country. As a result, the medfly has become a serious economic pest on a wide range of fruit trees in Syria (TALHOUK 1969). Despite the importance of this pest to Syrian agriculture, little is known about its seasonal occurrence, distribution and the damage it causes to fruit trees, particularly in the southern part of the country.

In this paper, we report data on population fluctuations of the medfly in southern Syria and the economic damage it causes to the most important fruit trees in this area. In addition, we examine the ability of this fly to overwinter in Damascus Ghota.

\section{Acknowledgemets}

The authors would like to thank Dr I. OTHMAN, Director General of the Syrian Atomic Energy Commission and Dr F. KuRDALI, Head of the Department of Agriculture for supporting this project. They would also like to thank Dr Z. AL-AHMADY (University of Damascus) and Dr W. ENKERLIN (Joint Division, FAO/IAEA) for their comments on an earlier version of this manuscript 


\section{MATERIALS AND METHODS}

\section{Study sites}

This study was conducted at several locations representing fruit production areas in the southern part of Syria (Table 1). In particular, it was carried out in Damascus Ghota (the cultivated area around the city of Damascus, $650 \mathrm{~m}$ ), Zabadani and Sargaiah (north-west of Damascus, 1150 and 1500 m respectively), Rankus (north of Damascus, $1500 \mathrm{~m}$ ), Orneh (south-west of Damascus, $1450 \mathrm{~m}$ ) and Ain Al-Arab (1 $500 \mathrm{~m}$ ) near the city of Swieda in the far south. Although all of these areas have a typical Mediterranean climate, certain environmental differences are very obvious owing to differences in altitude, particularly between Damascus Ghota and the other areas. Damascus Ghota has a hot dry summer, low precipitation in winter $(210 \mathrm{~mm})$, and temperatures occasionally fall below freezing. Winter in the other study areas is a lot colder with temperatures often falling below freezing, a higher precipitation rate $(550-750 \mathrm{~mm})$ and cooler summers.

Table 1. Number of medflies captured in the different study areas in 1999-2001.

\begin{tabular}{|l|c|c|c|}
\hline \multirow{2}{*}{ Area } & \multicolumn{3}{|c|}{ Year and number of captured flies during the season } \\
\cline { 2 - 4 } & $\mathbf{1 9 9 9}$ & $\mathbf{2 0 0 0}$ & $\mathbf{2 0 0 1}$ \\
\hline Damascus Ghota & 6805 & 4678 & 4875 \\
\hline Orneh & 36 & 0 & 27 \\
\hline Ain Al-Arab & 3 & 2 & 0 \\
\hline Sargaiah & 0 & 0 & 0 \\
\hline Zabadani & 0 & 0 & 0 \\
\hline Rankus & 0 & 0 & 12 \\
\hline
\end{tabular}

A wide variety of host fruits of the medfly grow in these areas, including stone fruits, pome fruits, figs Ficus carica L. and the cactus Opuntia vulgaris MILL. The fruiting season in Damascus Ghota starts in June and ends in November with apricots Prunus armeniaca L., peaches Prunus persica (L.) and plums Prunus domestica L. maturing first, and quince Cydonia oblonga MILL. and oriental persimmon Diospyros kaki THUNB. maturing last. In Zabadani, Sargaiah, Rankus, Orneh and Ain Al-Arab, however, apple Malus domestica BORKH. orchards occupy more than $85 \%$ of the cultivated land, while the remainder is mostly planted with cherry Prunus avium (L.), peach, pear Pyrus communis L., quince and a few other fruit trees. 


\section{Monitoring adults}

In each of the study areas, a number of Jackson traps (25-35) were installed every year in fruit tree orchards. The traps were suspended at a height of 1.5-2 $\mathrm{m}$ from the ground and baited with trimedlure dispensers (AgriSense, UK), which were replaced every four weeks. The traps were checked weekly, the caught flies removed, their number recorded and the sticky inserts replaced whenever necessary. In Damascus Ghota, because of the highly mixed agricultural system where orchards are small and, in most cases, different species of fruit trees are planted in the same orchard, the traps were left on the same selected trees during the entire season. In the other locations, however, the traps were moved during the growing season to new fruiting orchards. In general, they were moved from cherry to apricot to peach and plum and finally to pear, apple and quince orchards

Table 2. Fruit infestation with medfly larvae and mean number of larvae/fruit in Damascus Ghota during the three year study period (1999-2001). N - number of frutis examined, $\%$ - infestation [\%], Mean - mean no. of larvae/fruit.

\begin{tabular}{|l|c|c|c|}
\hline \multicolumn{1}{|c|}{ Fruit species } & N & \% & Mean \\
\hline Fig Ficus carica L. & 634 & 69.7 & 4.6 \\
\hline Oriental persimmon Diospyros kaki L.F. & 107 & 21.5 & 10.7 \\
\hline Peach Prunus persica (L.) & 148 & 17.4 & 4.9 \\
\hline Pear Pyrus communis L. & 109 & 11.9 & 4.5 \\
\hline Apple Malus domestica BORKH. & 160 & 0.0 & 0.0 \\
\hline Quince Cydonia oblonga MiLL. & 108 & 11.1 & 2.2 \\
\hline Apricots Prunus armeniaca L. & 650 & 3.1 & 1.9 \\
\hline Plum Prunus domestica L. & 320 & 1.9 & 1.8 \\
\hline Prickly pear Opuntia vulgaris MILL. & 259 & 1.2 & 1.6 \\
\hline Total & 2495 & - & - \\
\hline
\end{tabular}

\section{Fruit infestation}

The infestation rate of the different host fruits in Damascus Ghota was determined by the random collection of ripe or ripening fruits from trees and fruits recently fallen on to the ground. Fruit sampling was conducted weekly and fruits were collected from the orchards where the traps were placed (Table 2). The collected fruits were transferred to the laboratory, counted and placed individually in plastic containers. Two sizes of plastic containers were used depending on the size of the fruit $(13.5 \times 18 \times 4.5 \mathrm{~cm}$ and $8 \times 8 \times 11$ $\mathrm{cm})$. Each container had a $3 \mathrm{~cm}$ deep layer of dry fine sand at the bottom to serve as a pupation media for the mature larvae as they leave the fruits. The fruits were held at room temperature until all the larvae had completed their development and left the fruit (3-4 
weeks). The sand in the containers was sifted weekly, any larvae or pupae found were collected, counted, their number recorded and the percentage fruit infestation calculated by dividing the number of infested fruits (fruits with at least one medfly larva or pupa) by the total number of those examined. The mean number of larvae per fruit was calculated by dividing the total number of collected medfly larvae (or pupae) by the total number of infested fruits

\section{Sampling suspected host fruits as an overwintering refuge}

As no flies (except two) were caught in the Jackson traps from late December to early June in Damascus Ghota, we sampled the few fruits present on trees in the orchards during this period. In particular, we sampled fruits from prickly pear Opuntia vulgaris and bitter orange Citrus aurantium L., which are the most common fruits on trees during this period. Ripe fruits were collected directly from the trees, transferred to the lab, weighed and divided into samples about $0.5 \mathrm{~kg}$ each. Each sample was placed in a plastic container (13.5 $\mathrm{x} 18 \times 4.5 \mathrm{~cm}$ ) with $3 \mathrm{~cm}$ of fine dry sand at the bottom and left at room temperature for 6-8 weeks. The sand was sifted weekly for the presence of any medfly larvae or pupae, and any medfly instars present were counted and their number recorded. The percentage infestation was calculated by dividing the number of collected larvae (or pupae) by the amount ( $\mathrm{kg}$ ) of fruits examined.

\section{RESULTS}

Seasonal changes in the adult medfly population in Damascus Ghota during the years 1999-2001 are given in Figs 1a, 1b and 1c. These figures clearly show a similar population trend during the three years of the study: the first flies (males) were trapped in June and the last ones in December. In all years, populations peaked in August and then declined gradually at a relatively constant rate to lower densities at the beginning of September. Captures increased again towards mid to late November and then dropped sharply thereafter. In general, male captures were low in June, July and most of December, high from August to November, and absent from late December to early June.

Table 1 presents data on the number of captured flies (males) in the study areas during the three years of the investigation. The results show that, if we exclude Damascus Ghota, only a few flies were captured in the other locations. During the study period, a total of 16 358 flies (males) were captured in Damascus Ghota. The mean number of flies/trap/week was $3.73,3.60$ and 3.75 for the years 1999, 2000 and 2001 respectively. The average number of flies caught/trap/week in the three years of the study differed between tree 

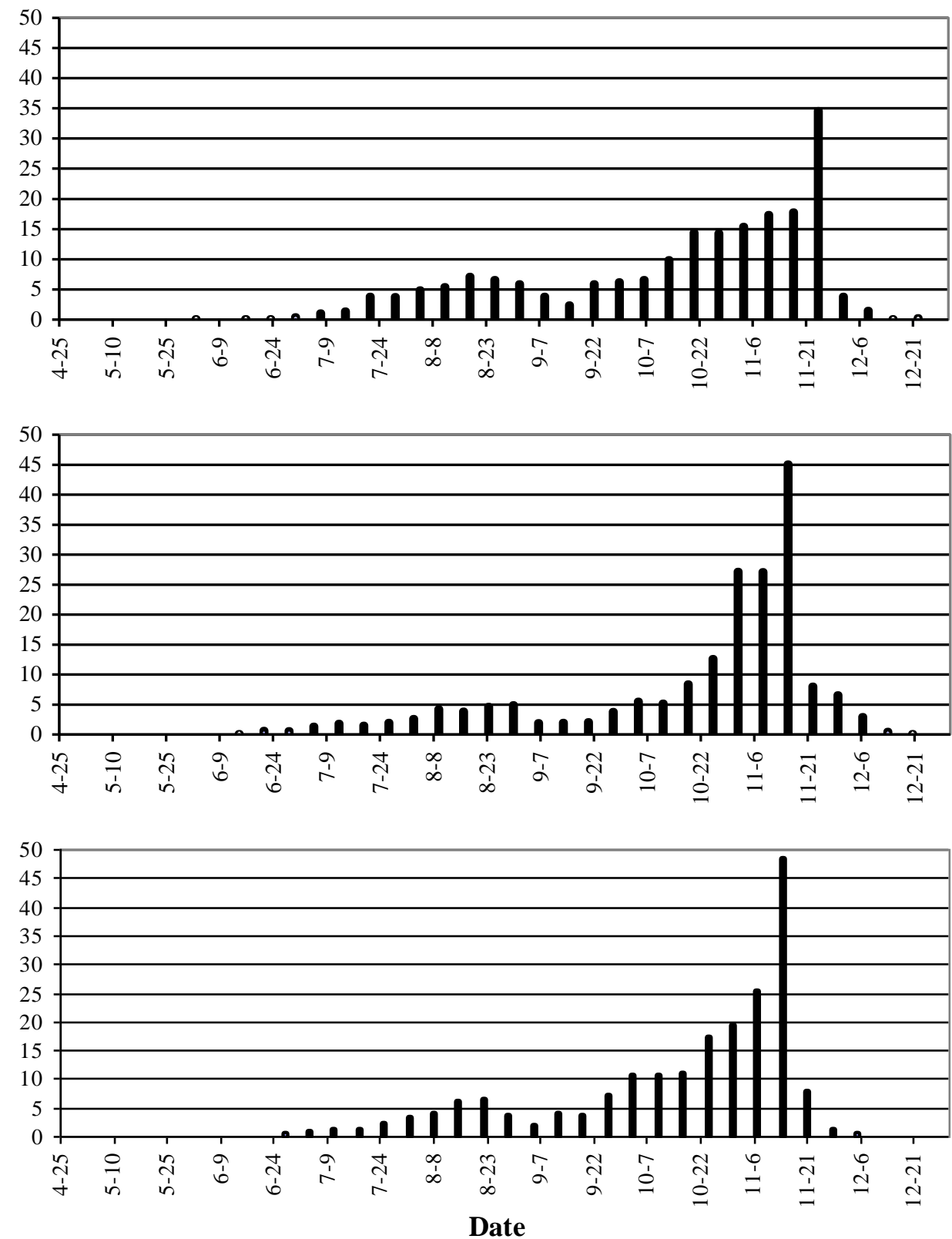

Fig. 1. Seasonal occurrence (mean numbers of flies/trap/week) of the Mediterranean fruit fly in Damascus Ghota in the year 1999 (upper diagram), 2000 (middle diagram), and 2001 (lower diagram). 
species and the sampling periods. Traps on certain trees caught more flies than others (Fig. 2). In particular, traps on fig and oriental persimmon trees caught the highest number of flies.

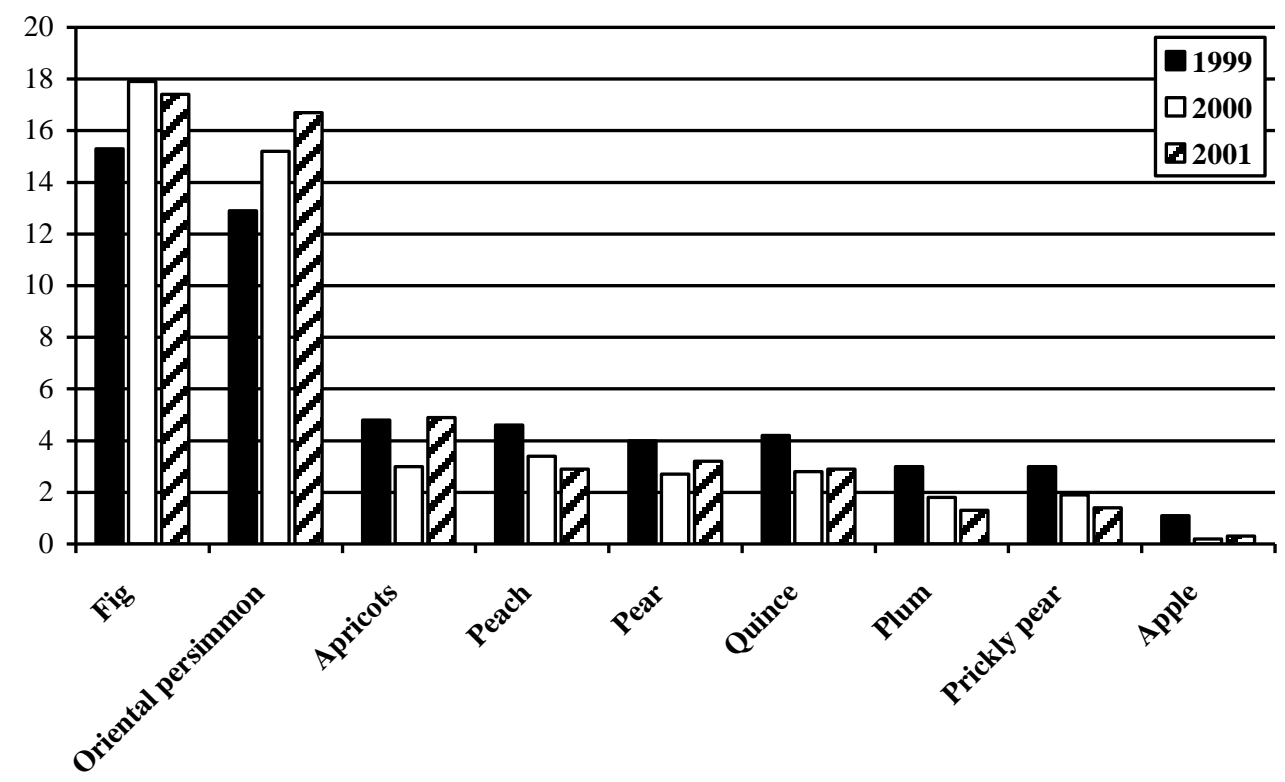

Fig. 2. Effects of host tree on the mean number of flies caught/week by Jackson traps on various tree species baited with trimedlure dispensers.

The first captured adults in Damascus Ghota in all years were recorded in traps installed on apricot trees. Apricots were the first fruit to ripen in Damascus Ghota and the first detected infestation in apricot was about the same time of the first adult capture. Traps placed on other fruit trees such as figs, pears, apples and oriental persimmon captured the first adults 2-4 weeks after the first adults were detected. Few flies were caught in traps placed in apple orchards, presumably because these had been heavily sprayed with insecticides. Later in the season, large numbers of adults were captured in traps placed on winter fig and oriental persimmon.

Table 2 presents data on fruit infestation with C. capitata larvae in Damascus Ghota. During the three years of the study, close to 2500 host fruits were collected. From these, a total of 2447 C. capitata pupae were obtained. Fig fruits had the highest infestation rate 
(69.7\%), followed by oriental persimmon (21.5\%), which yielded, on average, the highest number of pupae per infested fruit (10.7).

The results of data on percentage infestation in $>1100$ bitter orange fruit and $>1000$ prickly pear fruit (Table 3) collected during the three coldest months of the year (December - February) showed that a small overwintering larval population was present in prickly pear fruit. The number of larvae per fruit was relatively low ( 0.5 larvae $/ \mathrm{kg})$; however, the abundance of these fruits throughout the winter and their wide distribution in the area indicates that this host can contribute a number of flies that can give rise to the next season's medfly population.

Table 3. Results of sampling fruits for $C$. capitata larvae during the three coldest months of the year (Dec. - Feb. 2001). N1 - number of fruits examided, N2 - number of medflies found.

\begin{tabular}{|l|c|c|}
\hline \multicolumn{1}{|c|}{ Fruit species } & N1 & N2 \\
\hline Prickly pear Opuntia vulgaris MILL. & 1096 & 49 \\
\hline Bitter orange Citrus aurantium L. & 1138 & 0 \\
\hline
\end{tabular}

\section{DISCUSSION}

The medfly is one of the most serious fruit fly pests worldwide because of the great variety of host plants it attacks and its wide geographical distribution (LIQUIDO et al. 1991, SZYNISZEWSKA and TATEM 2014). Since its introduction to the eastern part of the Mediterranean in the $19^{\text {th }}$ century (FIMIANI 1989), this fly has become a serious pest on several fruit trees including citrus, stone fruits, pome fruits, figs and cactus (BODENHEIMER 1951). In Syria, this pest causes enormous economic damage to a wide range of agricultural crops, particularly citrus fruits in the coastal area (TALHOUK 1969). Despite the importance of this pest to Syrian agriculture, however, little is known about its distribution, seasonal occurrence and the damage it causes to fruit trees, particularly in the southern part of the country.

The current study shows that in southern Syria, particularly in Damascus Ghota, medfly populations follow a distinct seasonality pattern. Adults are active from early June to late December, very abundant from August to the end of November, and inactive, or below detectable levels throughout the rest of the year. During the period of adult activity, two peaks are noticeable. The first peak occurs in August and the second one in November with a much higher amplitude. This pattern of adult population fluctuation is similar to those reported from other Mediterranean counties (GRUNBERG 1938, RIVNAY, 1951, CAMPOS et 
al. 1989, MichelaKis 1991, DhOUIBI and GAHBICH 1994, MustaFA and ABDEL-JABBAR 1996, ISRAELY et al. 1997, KATSOYANNOS et al. 1998, AHMAD et al. 2001).

The seasonality pattern of the medfly population in the southern part of Syria, particularly in Damascus Ghota, seems to be influenced by temperature and host availability. With regard to the latter, medfly abundance appears to be closely associated with the seasonal maturation of the most suitable host fruits in the area, which are apricots, peaches, plums, figs and oriental persimmon. Early in the season (June and July), the fly breeds in apricots, plum and peach fruits. In late July and August, a large population builds up owing to the availability of mature figs. Fig fruit fluids provide an important source of nutrients for $C$. capitata (HENDRICHS and HENDRICHS 1990) and the fecundity and longevity of flies feeding on fig fruit were found to be relatively high (HENDRICHS et al. 1991). Later in the season, the population peaks in response to the availability of late fig varieties (winter fig) and oriental persimmon. In fact, host fruit phenology and availability have been shown to exert a great influence on the phenology and abundance of the medfly (HARRIS 1993).

Weather, particularly temperature, is also an important factor in medfly abundance. Despite the availability of host fruits during winter (prickly pear, bitter orange, loquat Eriobotrya japonica (THUNB.), citron Citrus medica L., hawthorn Crataegus sp., and other ornamental fruits), no fly activity (except in one case) was recorded between January and early June. The high temperature and low relative humidity during August also seem to affect the adult medfly population in the area, leading to a population decline in late August and early September. It has been shown (RIVNAY 1951, AVIDOV and HARPAZ 1969) that a continuous temperature above $33{ }^{\circ} \mathrm{C}$ shortens the life of medfly adults and reduces their fecundity and fertility. During August, the temperature often rises above $33{ }^{\circ} \mathrm{C}$ and sometimes above $40{ }^{\circ} \mathrm{C}$ in Damascus Ghota.

Information on $C$. capitata abundance was also gathered from host fruits collected from the vicinity of the traps. Based on the percentage infestation of the collected fruit and the number of emerged adults/fruit, the three most suitable host fruits for the medfly in this area are fig, oriental persimmon and peaches. These results go along with published reports, which suggest that although $C$. capitata has a very wide host range, females have strong preferences for certain host fruits (PROKOPY et al. 1994).

Two hypotheses have been suggested to explain the presence of medfly in the temperate regions of the world (HAGEN et al. 1981). Some scientists believe that the fly has become acclimatized to cold temperatures while others suggest that the presence of the fly in temperate regions is the result of repeated infestations of these regions during the warm months of the year. Although repeated infestation of the medfly in Damascus Ghota through citrus fruits coming from the coastal area is most certain, current evidence suggests that the fly may also survive relatively low winter temperatures in this area inside prickly 
pear fruit left on trees. A similar strategy for $C$. capitata larval survival was reported from Greece (PAPADOPOULOS et al. 1996, PAPADOPOUlOS 1998), where undecayed apple fruit fallen on the ground or left on the trees seem to play this role. Bitter oranges were also reported as an overwintering refuge for medfly larvae in Tunisia (HARRIS 1975). However, not a single larva was recovered from $>1100$ bitter orange fruits collected during the three coldest months of the year in Damascus Ghota in winter 2000-2001; similar results were also reported from Greece (ZERVAS et al. 1995). Prickly pear has been reported as a host of the medfly since early last century (BODENHEIMER 1930) and is heavily infested in the coastal area of Syria during summer. The importance of this host plant in southern Syria is related to its wide distribution and the occurrence of the stage suitable for oviposition when most other fruits have been harvested. Adult overwintering in C. capitata is another possibility (FIMIANI 1989). In fact, two medflies were captured in a Jackson trap after a few warm days in early February 2000.

Cold weather is an important factor limiting the distribution of the medfly. According to BodENHEIMER (1963), C. capitata is confined to areas where the climate allows two generations a year and does not interrupt development for more than 100 days. AVIDOV and HARPAZ (1969) reported that female medflies did not lay eggs at temperatures below $16{ }^{\circ} \mathrm{C}$, the adults became inactive at temperatures below $14{ }^{\circ} \mathrm{C}$ and flies could not survive temperatures below $5{ }^{\circ} \mathrm{C}$ for more than two weeks. BUYCKX (1994) also calculated that medfly adults could not survive in areas where the temperature fell below $10{ }^{\circ} \mathrm{C}$ for over 3 months. This may explain the absence, non-detection or low population levels of the medfly in Sargaiah, Zabadani, Rankus, Orneh and Ain Al-Arab. In these areas, temperatures drop below $5{ }^{\circ} \mathrm{C}$ and even below freezing for a long period of time during winter. It should be pointed out, however, that the lack of medfly detection in some of these areas (Zabadani and Sargaiah) may not necessarily mean that the fly was not there. Low population densities due to heavy insecticide spraying may have existed in these areas during summer and autumn without being detected by our monitoring tools. Trimedlure baited Jackson traps capture only males (about 50\% of the fly population) and these traps have been shown to be rather inefficient in detecting medfly adults when population densities are low (KATSOYANNOS et al. 1998).

To summarize, the medfly population in the southern part of Syria, particularly around Damascus, usually appears in June. It increases to large numbers in August, decreases in late August and early September, increases again thereafter until around mid to late November and disappears entirely around the end of December. The population build-up of the fly is determined mostly by the availability and abundance of the most preferred host fruit, and by environmental conditions, particularly temperature. In this study, the most important host fruits in the build-up of $C$. capitata populations were found to be peach, fig and oriental persimmon. Prickly pear fruit seem to enable larvae to survive the winter and 
bridge the gap between the autumn and spring generations. Overwintering in the adult stage, and/or reinfestation through citrus fruits being brought daily from the coastal area where the insect is active all year around, is another possibility.

\section{REFERENCES}

Ahmad M., Mofleh M., AJjan I. 2001. The relationships between Mediterranean fruit fly (Ceratitis capitata WiEDEMANN) (Diptera: Tephritidae) and its host plants in the coastal area of Syria. Arab Journal of Plant Protection 19(1): 27-34.

Avidov Z., HARPAZ I. 1969. Plant pests of Israel. Israel University Press, Jerusalem.

BODENHEIMER F.S. 1930. Die Schädlingsfauna Palästinas unter besonderer Berücksichtigung der Grossschädlinge des Mittelmeergebietes. Verlag Paul Parey, Berlin.

BODENHEIMER F.S. 1951. The Mediterranean fruit fly (Ceratitis capitata Wied.). [in:] F.S. BodenHeIMER (ed.). Citrus Entomology in the Middle East with special references to Egypt, Iran, Iraq, Palestine, Syria, Turkey. Dr W. Junk, The Hague, 87-160.

BODENHEIMER F.S. 1963. Ceratitis capitata in the Mediterranean basin. [in:] A. GrUNBERG (ed.). Report of the international conference on the Mediterranean fruit fly and San Jose scale. EPPO, Paris.

BUYCKX E.J. 1994. Chapter 12. Bioclimatic effects on the distribution of the Mediterranean fruit fly (Diptera: Tephritidae) in the Maghreb. [in:] C.O. Calkins, W. Klassen, P. Liedo (eds.). Fruit flies and the sterile insect technique. CRC Press, Boca Raton, Florida, 149-164.

CAmpos M., Ramos P., O.T. Jones 1989. Monitoring population of Ceratitis capitata in the Granada province of Spain using three different trapping systems. [in:] R. CAVALloro (ed.). Proceedings, Symposium: Fruit Flies of Economic Importance 87. Commission of the European Communities International Organization for Biological Control, International Symposium, 7-10 April 1987, Rome, Italy. Balkema, Rotterdam, The Netherlands, 401-404.

Dhouibi M.H., GAHBich H. 1994. Fluctuations des populations naturelles de la mouche méditerranéenne des fruits Ceratitis capitata WIED. (Diptera Trypetidae) dans deux biotopes du Nord de la Tunisie et évolution de l'infestation des Citrus. [in:] J. Piedade-Guerrreiro (ed.). Fruit flies of economic importance. IOBG/ WPRS Bulletin 17(6): 41-59.

EPPO 2009. Data Sheets on Quarantine Pests: Ceratitis capitata. Internet: http://www.eppo.int/ quarantine/insects/Geratitis capitata/GERTCA-ds.pdf

Fimiani P. 1989. Mediterranean region. [in:] A.S. Robinson, G. Hooper (eds.). Fruit flies: their biology, natural enemies and control. Vol. 3A. Elsevier, Amsterdam, 39-50.

Grunberg A. 1938. The Mediterranean fruit fly Ceratitis capitata (WIED.) in the Jordan Valley. Bulletin of Entomological Research 29(1): 63-76.

HARRIS E.J. 1975. Biotic factors influencing trends of the Mediterranean fruit fly, Ceratitis capitata (WIEDEMANN), in selected host habitats in Tunisia. Ph. D. dissertation, University of Hawaii, Mona. 
HARRIS E.J. 1993. Relationship between host plant fruiting phenology and Ceratitis capitata distribution and abundance in Hawaii. [in:] M. AluJA, P. LIEDO (eds.). Fruit flies: biology and management. Springer, New York, 137-143.

Hagen K.S., William W.W., Tassan R.L. 1981. Mediterranean fruit fly. The worst may be yet to come. California Agriculture 35(3): 5-7.

Hendrichs J., Hendrichs M.A. 1990. Mediterranean fruit fly (Diptera: Tephritidae) in nature: Location and diel pattern of feeding and other activities on fruiting and nonfruiting hosts and nonhosts. Annals of the Entomological Society of America 83(3): 632-641.

Hendrichs J., Katsoyannos B.I., PaPaj D.R., Prokopy R.J. 1991. Sex differences in movement between natural feeding and mating sites and tradeoffs between food consumption, mating success and predator evasion in Mediterranean fruit flies (Diptera: Tephritidae). Oecologia 86(2): 223-231.

IAEA [International Atomic Energy Agency] 2013. Tephritid Workers Database. Internet: http://nucleus.iaea.Org/sites/naipc/twd/Pages/default.aspx.

ISRAely N., Yuval B., Kitron U., Nestel D. 1997. Population fluctuations of adult Mediterranean fruit flies (Diptera: Tephritidae) in a Mediterranean heterogeneous agricultural region. Environmental Entomology 26(6): 1263-1269.

Katsoyannos B.I., Kouloussis N.A., CAREY J.R. 1998. Seasonal and annual occurrence of Mediterranean fruit fly (Diptera: Tephritidae) on Chios island: differences between two neighbouring citrus orchard. Annals of the Entomological Society of America 91(1): 43-51.

KARPATI J.F. 1983. The Mediterranean fruit fly (Its Importance, Detection and control). FAO, Rome, Italy.

KourTi A., LOUKAS M., Sourdis J. 1992. Dispersion pattern of medfly from its geographic center of origin and genetic relationships of the medfly with two close relatives. Entomologia Experimentalis et Applicata 63(1): 63-69.

Liquido N.J., Shinoda L.A., Cunningham R.T. 1991. Host plants of the Mediterranean fruit fly (Diptera: Tephritidae): an annotated world review. Miscellaneous publication 77. Entomological Society of America, Lanham, MD.

Michelakis S.E. 1991. Phenology of the Mediterranean fruit fly Ceratitis capitata WiEDEMANN in Crete. Israel Journal of Entomology 25-26: 177-180.

Mustafa T.M., AbDel-Jabbar S. 1996. Studies on some hosts of medfly Ceratitis capitata WiED. (Diptera: Tephritidae) in central highlands of Jordan. Arab Journal of Plant Protection 14(2): 91-95.

Papadopoulos N.T., CAREy J.R., Katsoyannos B.I., Kouloussis N.A. 1996. Overwintering of Ceratitis capitata (Diptera: Tephritidae) in northern Greece. Annals of the Entomological Society of America 89(4): 526-534.

Papadopoulos N.T., Katsoyannos B.I., CAREY J.R. 1998. Temporal changes in the composition of the overwintering larval population of the Mediterranean fruit fly (Diptera: Tephritidae) in northern Greece. Annals of the Entomological Society of America 91(4): 430-434.

Prokopy R.J., Roitberg B.D., VARGas R.I. 1994. Effect of egg load on finding and acceptance of host fruit in Ceratitis capitata flies. Physiological Entomology 19(2): 124-132. 
Rivnay E. 1951. The Mediterranean fruit fly in Israel. Bulletin of Entomological Research 41(2): $321-341$.

SzYNISZEWSKA A., TATEM S.J. 2014. Global assessment of seasonal potential distribution of Mediterranean fruit fly, Ceratitis capitata (Diptera: Tephritidae). PloS One 9(11): e111582.

TALHouk A.S. 1954. A list of insects found on plants of economic importance in Middle Eastern countries. Verlag Paul Parey, Hamburg und Berlin.

TALHOUK A.S. 1969. Insects and mites injurious to crops in the middle Eastern countries. Verlag Paul Parey, Hamburg und Berlin.

Zervas G.A., Kateva C., Christopoulos A.D. 1995. Ways of overwintering of medfly Ceratitis capitata (WIED.) (Dipt.: Tephritidae). The overwintering of larvae suspended fruits of citrus trees in Attica Greece. [in:] Proceedings, $5^{\text {th }}$ Panhellenic Entomological Congress, 8-10 November 1993, Athens, Greece. Greek Entomological Society, Athens, Greece, 105-112. (in Greek)

Received: 13 January 2016

Accepted: 16 March 2016 